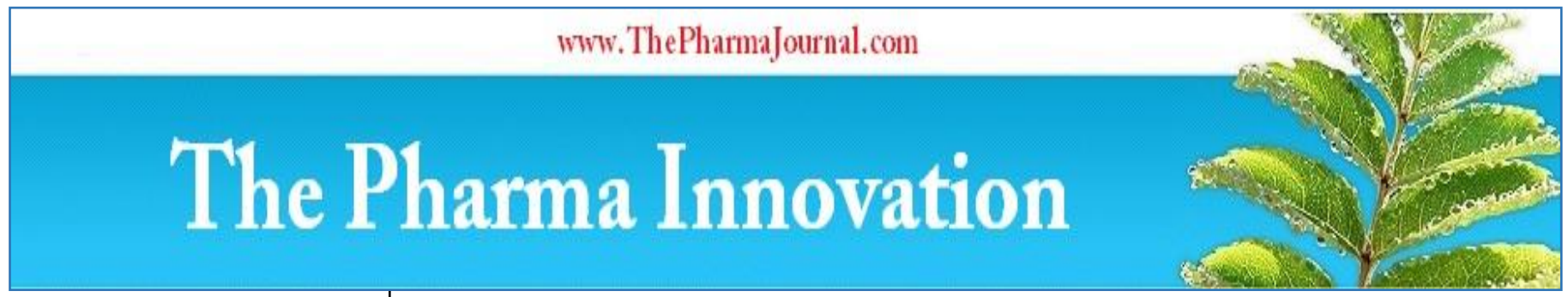

ISSN (E): 2277 - 7695

ISSN (P): 2349-8242

NAAS Rating: 5.23

TPI 2021; 10(4): 444-448

(C) $2021 \mathrm{TPI}$

www.thepharmajournal.com

Received: 04-02-2021

Accepted: 06-03-2021

\section{Nidhi Kujur}

Department of Genetics and

Plant Breeding, Indira Gandhi

Krishi Vishwavidyalaya, Raipur,

Chhattisgarh, India

\section{Alice Tirkey}

Department of Genetics and

Plant Breeding, Indira Gandhi

Krishi Vishwavidyalaya, Raipur,

Chhattisgarh, India

\section{Amita Ekka}

Department of Genetics and

Plant Breeding, Indira Gandhi

Krishi Vishwavidyalaya, Raipur,

Chhattisgarh, India
Corresponding Author:

\section{Nidhi Kujur}

Department of Genetics and

Plant Breeding, Indira Gandhi

Krishi Vishwavidyalaya, Raipur,

Chhattisgarh, India

\section{Assessment of genetic parameter of variation for root yield and quality traits of Ashwagandha [Withania somnifera $(\mathbf{L}$.$) Dunal]$}

\author{
Nidhi Kujur, Alice Tirkey and Amita Ekka
}

DOI: https://doi.org/10.22271/tpi.2021.v10.i4g.5974

\begin{abstract}
Ashwagandha is one of the important medicinal plant commercially cultivated from long period of time. Analysis of variance (ANOVA) was performed in Randomized Complete Block design for all the twenty one traits of sixty seven ashwagandha genotypes on Rabi 2016-2017, 2017-2018 and 2018-2019 were studied. The analysis of variance showed a wide range of variation and significant differences for all the traits under study, indicating the presence of sufficient amount of variability. Study estimates of phenotypic coefficient of variation (PCV) was greater than genotypic coefficient of variation (GCV) for all the traits, suggesting that the climate has a masking effect on expression of genetic variability. The difference was relatively small for certain traits and high for certain traits, it indicating that some traits were less influenced by the environment and some were highly influenced by the environment. High heritability with high genetic advance was due to additive gene action and selection for that particular desirable traits viz., fiber content in root $(\%)$, carbohydrate content in root $(\%)$, fresh plant weight per plant $(\mathrm{g})$, dry plant weight per plant $(\mathrm{g})$, fresh root weight per plant $(\mathrm{g})$ will be beneficial and effective to improve the root yield and quality.
\end{abstract}

Keywords: genetic variability, heritability, genetic advance, additive gene action

\section{Introduction}

Ashwgandha is one of the most important medicinal herbs and have a recognized medicinal properties for crude drugs and extracts. Ashwagandha belongs to family of "solanaceae" and genus of "Withania" and botanically known as Withania somnifera (L.) Dunal. It is a cross pollinated crop having the chromosome number $2 n=48$ (Nigam and Kandalkar 1995) ${ }^{[7]}$. It is originated from north-western and central India as well as Mediterranean region of Africa (Kumar et al., 2020) ${ }^{[5]}$. In view of extremely rich biodiversity in the state, the government has declared Chhattisgarh as "Herbal state" on July 2001. It is found in Baster Plateau of Chhattisgarh (Handbook on Medicinal and Aromatic Plant $3^{\text {rd }}$ edition). It is known as "Indian ginseng or "winter cherry" or "poison gooseberry". Ashwagandha is a "royal herb" because of its numerous rejuvenative effects on the human body possesses antioxidant, anxiolytic, adaptatgen, memory enhancing, antiparkinsdomia, antivenom, antinflamatory properties (Gupta and Rana 2007) ${ }^{[4]}$. Medicinal properties of ashwagandha root are attributed to the chemical quality i.e presence of total alkaloids (Singh and Kumar 1998) ${ }^{[9]}$. Market value of the root is based on physical quality i.e. root texture and root morphology brittle, robust length roots have high market value (Mishra et al., 1998) ${ }^{[6]}$.

The important factors restricting the large scale production and development of better cultivar it is because of less information available about genetic diversity, inter and intra-specific variability and genetic relationship among $W$. somnifera. Therefore, attempts are made to analyse genetic diversity for the improvement of the medicinal plant $W$. somnifera (Bhat et al., 2012) ${ }^{[1]}$ the present study was conducted to get an understanding on genetic architecture of root on the basis root yield, morphological, quality traits, which will facilitate genetic upgradation to develop superior cultivars benefitting both cultivators and consumers.

\section{Materials and Methods}

Sixty seven ashwagandha genotypes including three checks JA-20, RVA-100 JA-134 collected from different states of India were considered for the study. The experiment was carried out during Rabi 2016-17, 2017-18 and 2018-19 at research cum instructional farm, Department of 
Genetics and Plant Breeding, College of Agriculture, Indira Gandhi Krishi Vishwavidyalaya, Raipur (C.G.). These germplasm was planted with a spacing $30 \mathrm{cmX} 10 \mathrm{~cm}$ row to row and plant to plant. Randomly five plants were selected from each treatment for recording data for following traits viz., days to flowering, plant height $(\mathrm{cm})$, number of main branches per plant, number of secondary branches per plant, leaf length $(\mathrm{cm})$, leaf width $(\mathrm{cm})$, number of plant per plot, number of berries per plant, seed yield $(\mathrm{g})$, fresh plant weight $(\mathrm{g})$, dry plant weight $(\mathrm{g})$, main root length $(\mathrm{cm})$, main root diameter $(\mathrm{cm})$, root branches per plant, fresh root weight per plant $(\mathrm{g})$, dry root weight per plant $(\mathrm{g})$, fibre content in root $(\%)$, carbohydrate content in root $(\%)$, protein content in root $(\%)$, harvest index (\%) and dry matter content (\%). For statistical analysis, the individual plant observations from randomized block design experiment were analyzed statistically as per the procedure given by Cochran and Cox $(1957)^{[2]}$

\section{Result and Discussions}

Sixty seven ashwagandha genotypes were studied for variability analysis on Rabi-2017, 2018 and 2019 on the basis of various quality and yield characters.

\section{Analysis of variance}

Analysis of variance (ANOVA) was performed in Randomized Complete Block design for all the twenty one traits of sixty seven ashwagandha genotypes on Rabi 20162017, 2017-2018 and 2018-2019 were studied. The analysis of variance showed a wide range of variation and significant differences for all the traits under study, indicating the presence of sufficient amount of variability. The mean sum of square due to replications were non-significant for all the traits under studied. The result are presented in Table 1.

\section{Mean performance and range of genotype}

The mean performance and range of sixty seven ashwagandha genotype on Rabi 2016-2017, 2017-2018 and 2018-2019 with respect to twenty one traits/characters were studied and presented in Table 2.

Days to flowering: It varied from 95 to 104 with an average of 99 days. 104 (Acc.45) had maximum day's to 50\% flowering and 95 (Acc.30) had minimum day to $50 \%$ flowering.

Plant height (cm): Plant height varied 42.72 to 72.46 with an average of 56.78. The tallest genotypes was 72.46 (Acc.67) and shortest was 42.72 (Acc.28).

Number of main branches per plant: No. of main branches in upper region per plant varied from 1.77 to 3.00 with an average of 2.32. Maximum branch was observed in 3.00(Acc.4) and minimum branch was observed 1.77(Acc.3. Acc.57)

Number of secondary branches per plant: No. of secondary branches per plant varied from 4.17 to 12.17 with an average of 8.19. Maximum branch was observed in 12.17 (Acc.33) and minimum branch was observed 4.17 (Acc.11).

Leaf length (cm): Leaf length varied from 3.50 to 5.75 with an average of 4.65. 5.75 (Acc.44) had maximum and 3.50 (Acc.53) had minimum leaf length.
Leaf width (cm): Leaf width varied from 1.52 to 2.47 with an average of 1.97. 2.47 (Acc.45) had maximum and 1.52 (Acc.53) had minimum leaf width.

Number of plant per plot: It varied from 7.17 to 14.67 with an average of 10.74. The maximum weight was found in 14.67 (Acc.1) and minimum in 7.17 (Acc.36)

Number of berries per plant: It varied from 80.17 to 380.00 with an average of 192.16. The maximum weight was found in 380.00(Acc.67) and minimum in 80.17(Acc.55).

Seed yield per plant (g): It varied from 22.98 to 80.38 with an average of 38.93. The maximum weight was found in 80.38 (Acc.34) and minimum in 22.98 (Acc.6).

Fresh Plant weight per plant (g): Fresh plant weight varied from 28.60 to 198.78 with an average of 73.28. 198.78 (Acc.67) had maximum weight and had minimum weight in 28.60(Acc.55)

Dry Plant weight per plant (g): Dry plant weight varied from 6.87 to 29.39 with an average of 14.53. 29.39 (Acc.39) had maximum weight and had minimum weight 6.87(Acc.28)

Main Root length (cm): Main root length varied from 16.09 to 28.74 with an average of 21.59 . The longest root was found in 28.74 (Acc.11) and shortest root length found in 16.09 (Acc.6)

Main Root Diameter (cm): Main root diameter varied from 2.59 to 4.72 with an average of 3.47. The maximum root diameter was observed in genotype 4.72 (Acc.33) and had minimum in 2.59 (Acc.28)

Root Branches per plant: No. of root branches per plant varied from 5.18 to 11.12 with an average of 7.25 . The maximum root branches was recorded in 11.12 (Acc.24) and had minimum in. 5.18(Acc.56)

Fresh root weight per plant (g): Fresh root weight varied from 5.86 to 18.95 with an average of 10.57. 18.95 (Acc.33) had maximum weight and 5.86 (Acc.56) minimum weight.

Dry Root weight per plant (g): Dry root weight varied from 1.67 to 5.51 with an average of 2.76. 5.51(Acc.1) had maximum weight and 1.67(Acc.56) had minimum weight.

Fiber content in root $(\%)$ : Fiber content in root varied from 4. 85 to 28.25 with an average of 16.03. Maximum fiber content was observed in 28.25 (Acc.54) and had minimum in 4. 85 (Acc. 17)

Carbohydrate content in root (\%): Carbohydrate content in root varied from 12.74 to 38.63 with an average of 22.91 . 38.63 (Acc.12.) had maximum carbohydrate content and had minimum in 12.74 (Acc.42)

Protein content in root $(\%)$ : Protein content in root varied from 3.18 to 7.69 with an average of 5.14. The maximum Protein content was observed in 7.69 (Acc.18) and had minimum 3.18 (Acc.39) 
Harvest Index (\%): It varied from 8.63 to 26.48 with an average of 17.04. The maximum weight was found in 26.48 (Acc.41) and minimum in 8.63. (Acc.67)

Dry Matter content (\%): It varied from 12.72 to 47.06 with an average of 27.19. The maximum weight was found in 47.06 (Acc.1) and minimum in 12.72. (Acc.67).

\section{Phenotypic and Genotypic coefficient of variation}

The assessment of genotypic and phenotypic coefficient of variation gives us a plan of relative amount of inherited and non-inherited variation. Information on the nature and magnitude of genetic variability is of immense significant for initiating and breeding programme. In the present study estimates of phenotypic coefficient of variation (PCV) was greater than genotypic coefficient of variation $(\mathrm{GCV})$ for all the traits, but the difference was relatively small for certain traits and high for certain traits, it indicating that some traits were less influenced by the environment and some were highly influenced by the environment. The genotypic coefficient of variation was lower than the phenotypic coefficient of variation, suggesting that the climate has a masking effect on expression of genetic variability.

In this study, the highest phenotypic coefficient of variation recorded in number of berry per plant $(61.32 \%)$ and genotypic coefficient of variation was recorded for fresh plant weight $(\mathrm{g})(43.12 \%)$ indicating the presence of considerable genetic variability. Similarly Sangwan et al., (2013) ${ }^{[8]}$ observed the high PCV and GCV for the number of berries per plant. In this study, the lowest phenotypic coefficient of variation (3.43) and genotypic coefficient of variation (1.04) was recorded for days to flowering.

Table 1: Pooled Analysis of variance (ANOVA) for root yield and quality traits of ashwagandha

\begin{tabular}{|c|c|c|c|c|}
\hline SI. No. & Character & Replication $(\boldsymbol{d} f=\mathbf{1})$ & Treatment $(\boldsymbol{d f}=\mathbf{6 6})$ & Pooled Error $(\boldsymbol{d} f=\mathbf{3 3 0})$ \\
\hline 1 & DAY_FLW & 0.3 & $16.764^{* *}$ & 10.393 \\
\hline 2 & PLT_HGT & 0.001 & $247.351^{* * *}$ & $0.645^{* *}$ \\
\hline 3 & BRN_PLT & 0.046 & $20.661^{* * *}$ & 4.059 \\
\hline 4 & SBRN_PLT & 0.022 & $1.660^{* * *}$ & 0.333 \\
\hline 5 & LF_LT & 0.037 & $0.267 * * *$ & 0.088 \\
\hline 6 & LF_WD & 0.162 & $17.541^{* * *}$ & 7.123 \\
\hline 7 & PLT_PLOT & 0.002 & $28585.112^{* * *}$ & 10945.592 \\
\hline 8 & BERR_PLT & 427.141 & $723.455^{* * *}$ & 194.522 \\
\hline 9 & SED_YLD & 10.856 & $6621.598^{* * *}$ & 632.81 \\
\hline 10 & PLT_WTF & 0.049 & $180.965^{* * *}$ & 13.444 \\
\hline 11 & PLT_WTD & 0.117 & $35.156^{* * *}$ & 8.838 \\
\hline 12 & ROT_LT & 0.009 & $1.232^{* * *}$ & 0.369 \\
\hline 13 & ROT_DIA & 0.086 & $10.267^{* * *}$ & 2.967 \\
\hline 14 & ROT_PLT & 0.105 & $52.971^{* * *}$ & 4.659 \\
\hline 15 & ROT_WGTF & 0.003 & $2.136^{* * *}$ & 0.631 \\
\hline 16 & ROT_WGTD & 0.075 & $190.784^{* * *}$ & 1.409 \\
\hline 17 & FIB\% & 0.894 & $162.554^{* * *}$ & 8.7 \\
\hline 18 & CARBO\% & 0.035 & $10.178^{* * *}$ & 0.115 \\
\hline 19 & PRO\% & 0.243 & $113.646^{* * *}$ & 46.271 \\
\hline 20 & HI\% & 8.218 & $278.574^{* * *}$ & 55.828 \\
\hline 21 & DMC\% & 83.969 & & \\
\hline
\end{tabular}

$*, * * \& * * *$ represent significant at $5 \%, 1 \% \& 0.5 \%$ respectively. $d f$ - degree of freedom

1. DAY_FLW: Days to flowering

2. PLT_HGT: Plant height $(\mathrm{cm})$

3. BRN_PLT: Number of main branches per plant

4. SBRN_PLT: Number of secondary branches per plant

5. LF_LT: Leaf length $(\mathrm{cm})$

6. LF_WD: Leaf width $(\mathrm{cm})$

7. PLT_PLOT: Number of plant per plot

8. BERR_PLT: Number of berries per plant

9. SED_YLD: Seed yield per plant $(\mathrm{g})$

10. PLT_WTF: Fresh plant weight $(\mathrm{g})$

11. PLT_WTD: Dry plant weight $(\mathrm{g})$

12. ROT_LT: Main root length $(\mathrm{cm})$

13. ROT_DIA: Main root diameter $(\mathrm{cm})$

14. ROT_PLT: Root branches per plant

15. ROT_WGTF: Fresh root weight (g)

16. ROT_WGTD: Dry root weight (g)

17. FIB \%: Fibre content in $\operatorname{root}(\%)$

18. CARBO\%: Carbohydrate content in root (\%)

19. PRO\%: Protein content in root (\%)

20. HI\%: Harvest index (\%) and

21. DMC\%: Dry matter content $(\%)$ 
Table 2: Genetic Parameter of variation of pooled data

\begin{tabular}{|c|c|c|c|c|c|c|c|c|c|}
\hline SI. No. & Character & Mean & \multicolumn{2}{|c|}{ Range } & PCV (\%) & GCV (\%) & $\mathbf{h}^{2}(\mathbf{b s})$ & $\mathbf{h}^{\mathbf{2}}(\mathbf{b s})(\boldsymbol{\%})$ & GA as \% of mean \\
\hline & & & MIN & MAX & & & & & \\
\hline 1 & DAY_FLW & 98.78 & 94.67 & 103.5 & 3.43 & 1.04 & 0.09 & 09.00 & 0.66 \\
\hline 2 & PLT_HGT & 56.78 & 42.72 & 72.46 & 20.99 & 8.08 & 0.15 & 15.00 & 6.41 \\
\hline 3 & BRN_PLT & 2.32 & 1.77 & 3 & 28.46 & 8.88 & 0.09 & 09.00 & 5.64 \\
\hline 4 & SBRN_PLT & 8.19 & 4.17 & 12.17 & 31.88 & 20.29 & 0.41 & 41.00 & 26.62 \\
\hline 5 & LF_LT & 4.65 & 3.5 & 5.75 & 16.01 & 10.11 & 0.39 & 39.00 & 13.15 \\
\hline 6 & LF_WD & 1.97 & 1.52 & 2.47 & 17.46 & 8.76 & 0.25 & 25.00 & 9.06 \\
\hline 7 & PLT_PLOT & 10.74 & 7.17 & 14.67 & 27.72 & 12.27 & 0.19 & 19.00 & 11.19 \\
\hline 8 & BERR_PLT & 192.16 & 80.17 & 380 & 61.32 & 28.22 & 0.21 & 21.00 & 26.75 \\
\hline 9 & SED_YLD & 38.93 & 22.98 & 80.38 & 43.19 & 24.12 & 0.31 & 31.00 & \\
\hline 10 & PLT_WTF & 73.28 & 28.6 & 198.78 & 55.11 & 43.12 & 0.61 & 61.00 & 27.75 \\
\hline 11 & PLT_WTD & 14.53 & 6.87 & 29.39 & 44.27 & 36.37 & 0.68 & 68.00 & 69.48 \\
\hline 12 & ROT_LT & 21.59 & 16.09 & 28.74 & 16.84 & 9.7 & 0.33 & 33.00 & 61.56 \\
\hline 13 & ROT_DIA & 3.47 & 2.59 & 4.72 & 20.67 & 10.93 & 0.28 & 28.00 & 11.51 \\
\hline 14 & ROT_PLT & 7.25 & 5.18 & 11.12 & 28.23 & 15.23 & 0.29 & 29.00 & 11.91 \\
\hline 15 & ROT_WGTF & 10.57 & 5.86 & 18.95 & 33.74 & 26.86 & 0.63 & 63.00 & 16.92 \\
\hline 16 & ROT_WGTD & 2.76 & 1.67 & 5.5 & 33.97 & 18.12 & 0.29 & 29.00 & 44.03 \\
\hline 17 & FIB\% & 16.03 & 4.85 & 28.25 & 35.82 & 35.95 & 0.96 & 96.00 & 19.91 \\
\hline 18 & CARBO\% & 22.91 & 12.74 & 38.63 & 25.58 & 22.11 & 0.75 & 75.00 & 70.63 \\
\hline 19 & PRO\% & 5.14 & 3.18 & 7.69 & 26.05 & 25.2 & 0.09 & 09.00 & 39.35 \\
\hline 20 & HI\% & 17.04 & 8.63 & 26.48 & 44.49 & 19.66 & 0.19 & 19.00 & 50.23 \\
\hline 21 & DMC\% & 27.19 & 12.72 & 47.06 & 35.45 & 22.4 & 0.39 & 39.00 & 17.9 \\
\hline
\end{tabular}

PCV: Phenotypic coefficient of variation, GCV: Genotypic coefficient of variation, $\mathbf{h}^{\mathbf{2}}$ (bs): Heritability in broad sense, GA: Genetic advance

1. DAY_FLW: Days to flowering

2. PLT_HGT: Plant height $(\mathrm{cm})$

3. BRN_PLT: Number of main branches per plant

4. SBRN_PLT: Number of secondary branches per plant

5. LF_LT: Leaf length $(\mathrm{cm})$

6. LF_WD: Leaf width $(\mathrm{cm})$

7. PLT_PLOT: Number of plant per plot

8. BERR_PLT: Number of berries per plant

9. SED_YLD: Seed yield per plant (g)

10. PLT_WTF: Fresh plant weight $(\mathrm{g})$

11. PLT_WTD: Dry plant weight (g)

12. ROT_LT: Main root length $(\mathrm{cm})$

13. ROT_DIA: Main root diameter $(\mathrm{cm})$

14. ROT_PLT: Root branches per plant

15. ROT_WGTF: Fresh root weight (g)

16. ROT_WGTD: Dry root weight $(\mathrm{g})$

17. FIB \%: Fibre content in root (\%)

18. CARBO\%: Carbohydrate content in root (\%)

19. PRO\%: Protein content in root (\%)

20. HI\%: Harvest index $(\%)$ and

21. DMC\%: Dry matter content (\%)

The calculated phenotypic and genotypic coefficient of variation for root yield and quality traits has been presented in Table 2.

\section{Heritability (broad sense) and genetic advance as percent of mean}

Heritability (broad sense) and genetic advance as percent of mean are important section parameters. Heritability estimation along with genetic advance as percent of mean are more powerful for pretending the genetic gain under selection.

From the analysis, high heritability coupled with high genetic advance as percent of mean was recorded in fiber content in root $(96.00 \% ; 70.63 \%)$, carbohydrate content in root $(75.00 \%$; $39.35 \%)$, dry plant weight $(68.00 \% ; 61.56 \%)$, fresh root weight per plant $(63.00 \% ; 44.03 \%)$, fresh plant weight $(61.00 \%$; 69.48\%). High heritability with high genetic advance is evidence for heritability was due to additive gene action and selection for that particular desirable trait will be beneficial and effective. Similarly, Dubey (2007) reported reported high heritability with high genetic advance for dry root yield. Sangwan et al., (2013) [8] also reported high heritability and high genetic advance for fresh root yield/plant, biomass yield.

The lowest genetic advance as percent of mean was recorded for leaf width (cm) (9.06\%), plant height $(\mathrm{cm})(6.41 \%)$, number of main branches per plant $(5.64 \%)$ and days to flowering $(0.66 \%)$, suggested that the character of that selection was heavily affected by the environment in not being beneficial for that phenotype. This specify that traits is due to non-additive gene and heterosis breeding programme is useful for this. Similar finding reported by Ekka et al., (2021) [3].

Low heritability with high genetic advance as percent of mean was recorded in protein content in root $(09.00 \%$; $50.23 \%)$. Low heritability with low genetic advance as percent of mean was recorded in days to flowering $(09.00 \% ; 0.66 \%)$, number of main branches per plant $(09.00 \% ; 5.64 \%)$, plant height $(15.00 \% ; 6.41 \%)$ and leaf width $(25.00 \% ; 9.06 \%)$ indicates that character was highly influenced by the environment and 
selection is not effective for that traits. This results are in agreement with the finding Sangwan et al., $2013^{[8]}$.

\section{Conclusion}

From the above interpretation on genetic parameter, genetic variability and coefficient of variation for root yield and quality traits in ashwagandha germplasm existence of maximum variability recorded in day to $50 \%$ flowering, number of berry per plant, fresh plant weight $(\mathrm{g})$, dry plant weight $(\mathrm{g})$, fresh root weight per plant $(\mathrm{g})$, fiber content in root $(\%)$, carbohydrate content in $\operatorname{root}(\%)$.

\section{References}

1. Bhat TM, Kudesia R, Dar SA. Evaluation of genetic diversity among accessions of Withania somnifera L. (Dunal) using biochemical analysis and molecular markers. American-Eurasian J Agric. \& Environ. Sci 2012;12(7):983-990.

2. Cochran WG, Cox GM. Experimental Designs. Asia Publication House, Bombay 1957.

3. Ekka A, Tirkey A, Kujur N. Cluster and principal component analysis (PCA) in ashwagandha [Withania somnifera (L.) Dunal] for root traits. IJCS 2021;9(1):3012-3016.

4. Gupta GL, Rana AC. Withania somnifera (Ashwagandha): A Review. Pharmacognosy Reviews 2007;1(1):129-136.

5. Kumar M, Patel M, Chauhan R, Tank C, Solanki S, Patel $\mathrm{P}$ et al. Elucidation of genotype-environment interactions and genetic stability parameter of yield, quality and agromorphological traits in ashwagandha [Withania somnifera (L.) Dunal]. Journal of Genetics 2020;99:59.

6. Mishra HO, Sharma JR, Lal RK, Sharma S. Genetic variability and path analysis in asgandh (Withania somnifera). Journal of Medicinal and Aromatic Plant Sciences (India), ISSN 0253-7125, v 1998;20(3):753756.

7. Nigam KB, Kandalkar VS. Ashwagandha-Advances in horticulture, Vol. 11. Medicinal and Aromatic plants. Malhotra publishing House, New Delhi, India 1995, 337344.

8. Sangwan O, Avtar R, Singh A. Genetic variability, character association and path analysis in ashwagandha [Withania somnifera (L.) Dunal] under rainfed conditions. Research in Plant Biology 2013;3(2):32-36.

9. Singh S, Kumar KS. Withania somnifera - The Indian ginseng ashwagandha. Central Institute of Medicinal and Aromatic Plants, Lucknow, India 1998. 